\title{
Synthesis of 3-epi-Hypatulin B Featuring a Late-Stage Photo-Oxida- tion in Flow
}

\author{
Stefan Leisering, Sebastian Ponath, Kamar Shakeri, Alexandros Mavroskoufis, \\ Merlin Kleoff, Patrick Voßnacker, Simon Steinhauer, Manuela Weber, Mathias \\ Christmann*
}

Institute of Chemistry and Biochemistry, Freie Universität Berlin, Takustraße 3, 14195 Berlin, Germany

Supporting Information Placeholder

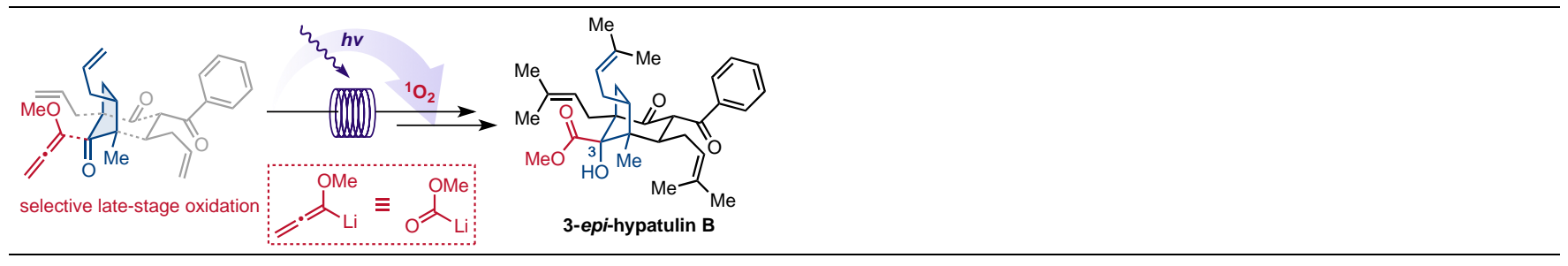

ABSTRACT: A total synthesis of 3-epi-hypatulin B, a highly oxygenated and densely functionalized bicyclic scaffold, is reported. The carbon skeleton was prepared by functionalization of a cyclopentanone core and an intramolecular Mukaiyama aldol reaction. The synthesis features a late-stage photo-oxidation of a methoxyallene intermediate for the installation of an ester functionality. Problems encountered during the batch process were solved by translation of the transformation into a flow protocol. Our synthesis highlights the value of flow chemistry to enable challenging steps in natural product synthesis.

Polycyclic polyprenylated acylphloroglucinols (PPAPs) are a family of meroterpenoids with fascinating and complex chemical structures. ${ }^{1}$ Due to a wide range of intriguing biological activities, PPAPs represent potential lead structures for neuroscience, infectious disease, and oncology drug discovery programs. ${ }^{2}$ Thus, several synthetic approaches, some of which culminated in elegant total syntheses, have been devised. ${ }^{3}$ The most prominent congener, the neuroactive hyperforin (1), is one of the main bioactive compounds in Hypericum perforatum (St. John's wort) (Scheme 1). ${ }^{4}$ While many of the isolated PPAPs retain the six-membered ring of their acylphloroglucinol progenitors, subsequent rearrangements and oxidative cleavages can result in ring expansions, contractions, or ring openings. ${ }^{5}$

In 2016, Tanaka, Kashiwada, and co-workers reported the isolation of two novel meroterpenoids with a contracted acylphloroglucinol- and a seco-acylphloroglucinol-derived motif, respectively, from the leaves of $h y$ pericum patalum. ${ }^{6}$ Whereas hypatulin A (2) has a highly oxygenated tricyclic octahydro-1,5-methanopentalene core, hypatulin B (3) possesses a bicyclo[3.2.1]octane motif. Both natural products have a densely substituted cyclopentane core bearing four stereocenters, three of them being quaternary (Scheme 1 ).

Hypatulin A (2) and B (3) were evaluated for their antimicrobacterial activity on strains of Staphylococcus aureus, Bacillus subtilis, and Escherichia coli. Hypatulin A exhibited activity against Bacillus subtilis.

According to Tanaka, Kashiwada, and co-workers hypatulin B (3) could be produced by oxidative cleavage and methylation through a biogenetic pathway from hypatulin A (2). The structural assignment of C-3 was supported by chemical conversion of hypatulin $A(2)$ into hypatulin $B(3)$ by a retro-Dieckmann-type cleavage using $\mathrm{N}, \mathrm{N}$-dimethylaminopyridine (DMAP) in $\mathrm{MeOH}$.

We speculated that the easier accessible hypatulin $B$ (3) could be transformed into hypatulin A (2) via cyclization. Simplification of hypatulin $B$ (3) by 
methoxycarbonylation and subsequent metathesis would lead to triketone 4 . Construction of the bicyclic scaffold was envisaged by a Dieckmann-type cyclization and installation of the substituents was intended by stereoselective functionalizations of ketone 5 (Scheme 1).

Scheme 1. Different PPAPs and Retrosynthetic Analysis of Hypatulin A (2) and Hypatulin B (3)

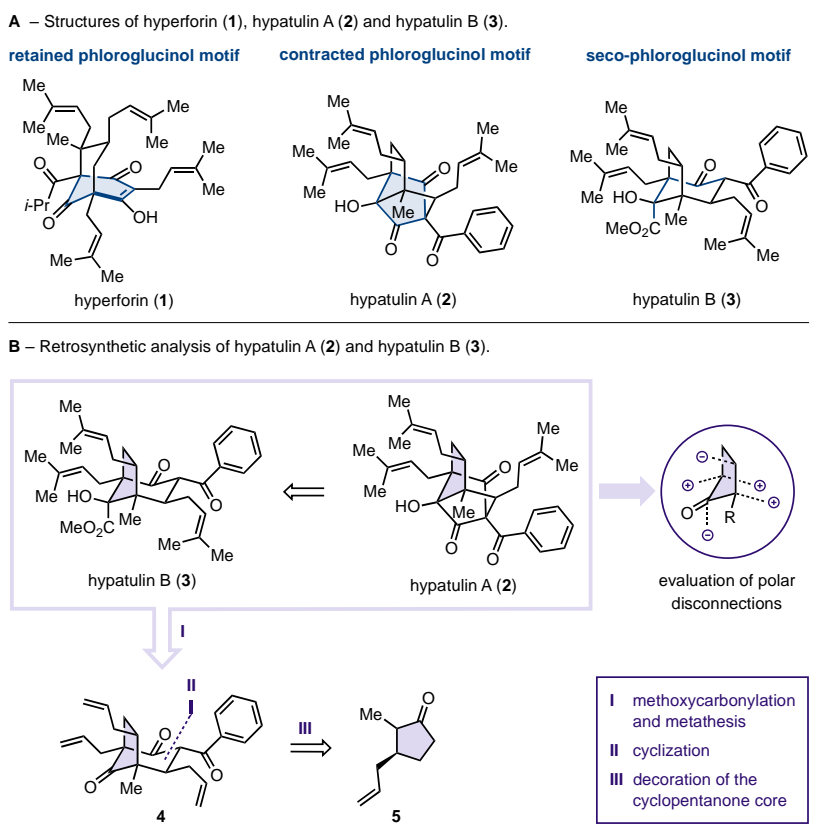

The synthesis commenced with cyclopentanone 5, which was prepared in $97 \%$ enantiomeric excess in analogy to a procedure by Taber and co-workers in four steps starting from 2-cyclopentenone. ${ }^{7}$ Enolization under thermodynamic control afforded silyl enol ether 6 in $94 \%$ yield and in a 93:7 ratio of constitutional isomers (Scheme 2). ${ }^{8}$ Subsequent Mukaiyama aldol addition with aldehyde 7 proceeded in $91 \%$ yield and generated the first of three quarternary stereocenters of the cyclopentane core. A 3:2-mixture of two diastereomers was obtained, providing, after separation, one diastereomer as a crystalline solid. X-ray crystal structure analysis revealed $(10 R)-8$ to possess the desired cis-relationship between methyl and allyl substituent. Both diastereomers were subjected to a tandem deacetalization/elimination affording enone 9. As both diastereomers $\mathbf{8}$ converge into enone $\mathbf{9}$, it can be deduced that they are diastereomers at $\mathrm{C}-10$, thus rendering the low diastereoselectivity inconsequential for the further synthesis (Scheme 2). With enone 9 in hand, construction of the second quarternary center bearing a methyl ester and an allyl group was pursued. Initial attempts to install the ester first, followed by an allylation resulted in the exclusive formation of the undesired diastereomer. Thus, the order of the electrophile additions was reversed. Interestingly, allylation of the corresponding enolate with allyl iodide in the presence of $N, N^{\prime}$-dimethylpropyleneurea (DMPU) at $-78^{\circ} \mathrm{C}$ gave a mixture of unreacted starting material, mono-, and bisallylated products. However, by decreasing the reaction temperature to $-100{ }^{\circ} \mathrm{C}$ monoallylation was achieved exclusively. Subsequent methoxycarbonylation was performed by deprotonation with NaHMDS and treatment with methyl cyanoformate providing the desired isomer $\mathbf{1 0}$ in 59\% over two steps (Scheme 3).

Scheme 2. Synthesis of Enone 9 (Thermal Ellipsoids at 50\% Probability)

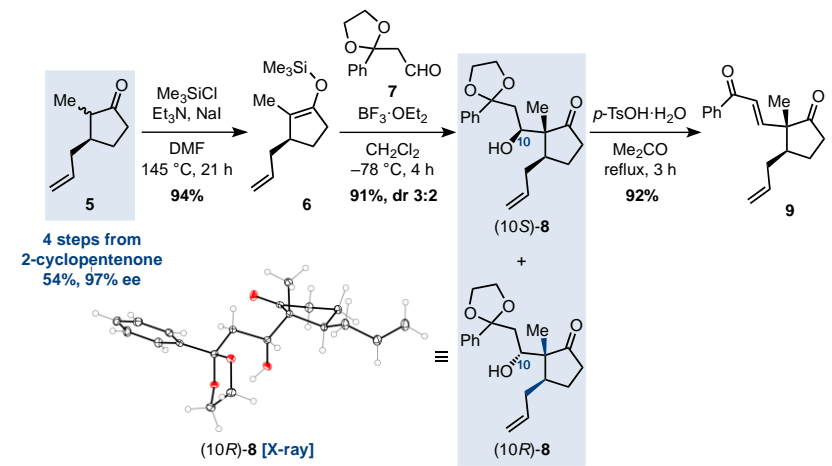

Attempts to telescope both reactions into an one-pot protocol ${ }^{9}$ revealed that the allylation step requires DMPU as solvent, while methoxycarbonylation in the presence of DMPU resulted in degradation (Scheme 3).

An attempted conjugate addition of an allyl cuprate to the enone $\mathbf{1 0}$ failed and provided exclusively the corresponding 1,2-addition product. Therefore, a HosomiSakurai reaction with allyltrimethylsilane was investigated. ${ }^{10} \mathrm{~A}$ screening of various Lewis acids, including titanium tetrachloride, ${ }^{10}$ boron trifluoride diethyl etherate, iron(III) chloride, ${ }^{11}$ iodine,$^{12}$ and indium, ${ }^{13}$ revealed indium(III) chloride ${ }^{14}$ in the presence of trimethylsilyl chloride to be the best system. Under these conditions, the 1,4-addition product $\mathbf{1 1}$ was isolated in $58 \%$ yield as a mixture of two diastereomers ( $\mathrm{dr} 1: 2.4$ ) (Scheme 3). During the reaction, partial trapping of the enolate with trimethylsilyl chloride was observed. When triethylamine was added after completion of the conjugate addition, silyl enol ether $\mathbf{1 2}$ was obtained exclusively in $63 \%$ yield as a mixture of two diastereomers (dr 1:2) (Scheme 3). The configuration was determined three steps later by $\mathrm{X}$-ray crystallographic analysis of intermediate 4. Unfortunately, the desired product turned out to be the minor diastereomer. Attempts to reverse the stereoselectivity were unsuccessful.

Next, we aimed to construct bicyclic triketone $\mathbf{4}$ in a Dieckmann-type cyclization of the highly substituted cy- 
Scheme 3. Synthesis of Key Intermediate Triketone 4 (Thermal Ellipsoids at 50\% Probability; Disorder Was Obmitted for Clarity) $)^{16}$

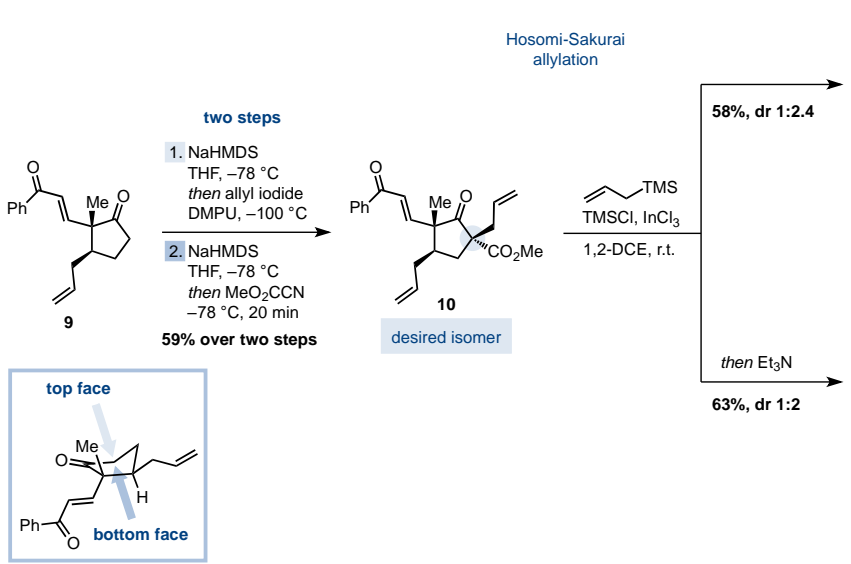

clopentanone $11 .{ }^{15}$ Unfortunately, a variety of different conditions resulted in the formation of $\mathbf{1 3}$ (Scheme 3). To suppress decarboxylation, reduction of the ester to the corresponding aldehyde and subsequent aldol cyclization was attempted. When ester 12 was treated with DIBAL-H at $-78{ }^{\circ} \mathrm{C}$, overreduction to the primary alcohol was a major side reaction. By lowering the temperature to $-100^{\circ} \mathrm{C}$, the corresponding aldehyde could be isolated in $70 \%$ yield. The subsequent intramolecular Mukaiyama aldol reaction with boron trifluoride etherate afforded a mixture of epimeric $\beta$-hydroxy ketones. ${ }^{17}$ Oxidation of the crude mixture of both epimers with Dess-Martin periodinane (DMP) ${ }^{18}$ eventually gave triketone 4 in $62 \%$ yield over three steps (Scheme 3).

With the bicyclic carbon framework assembled, the introduction of the remaining carbonyl functionality was addressed. Different d1-reagents either as acyl anion equivalents or masked carbonyl equivalents were considered. ${ }^{19}$ While bulky reagents such as lithiated dithiane ${ }^{20}$ gave no conversion, smaller nucleophiles such as methoxyallenyllithium ${ }^{21}$ or cyanide were added successfully to the ketone (Scheme 4). In all cases, the 1,3diketone was 'disarmed' by in situ deprotonation with NaHMDS. Unfortunately, X-ray and NMR analysis revealed that addition of all nucelophiles proceeded with the undesired facial selectivity. As all our attempts to obtain the epimeric tertiary alcohol were unsuccessful, we redirected our synthetic efforts towards 3-epi-hypatulin B (17).

Attempted conversion of cyanohydrine 14 to the corresponding ester $\mathbf{1 6}$ resulted in the desilylation and cyanide elimination leading to ketone 4 . In contrast, the addition of methoxyallenyllithium is irreversible and methoxyallene $\mathbf{1 5}$ was isolated in $72 \%$ yield (Scheme 4 ).

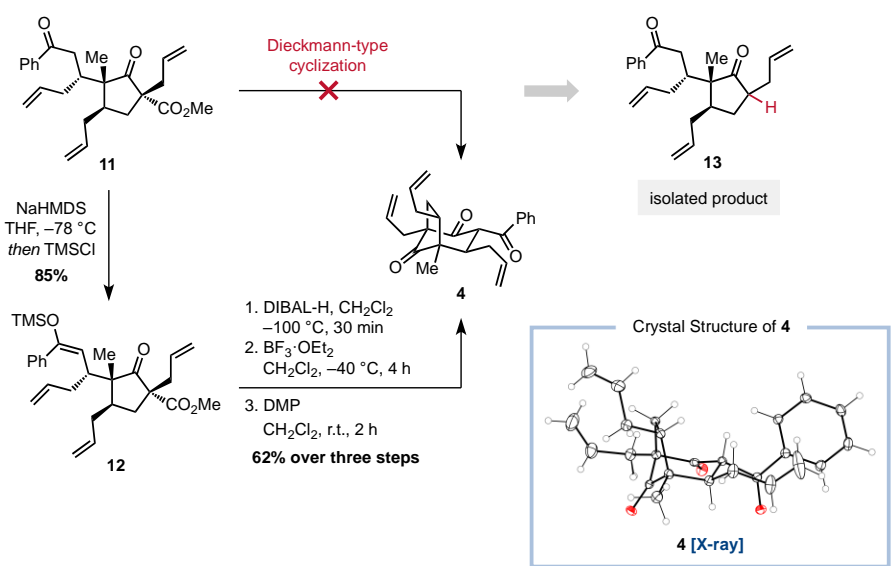

Next, we attempted the oxidative cleavage of the allenyl moiety to the corresponding ester $16 .{ }^{22}$ Although examples for ozonolysis of enol ethers in the presence of less electron-rich olefins have been reported, controlled addition of a solution of ozone, even at $-115^{\circ} \mathrm{C}$, resulted in complete degradation of the starting material. ${ }^{23}$ Alternatively, enol ethers can be reacted with singlet oxygen leading to dioxetanes, which decompose to the corresponding esters. ${ }^{24}$ Singlet oxygen exhibits high chemo- and regioselectivity depending on substitution patterns, conformations and stereoelectronic effects of the substrates. ${ }^{25}$ Gratifyingly, when methoxyallene $\mathbf{1 5}$ was treated with singlet oxygen generated with tetraphenylporphyrin (TPP) as photocatalyst in a test reaction the product could be isolated. As we experienced scale-up problems on a scale larger than $10 \mathrm{mg}$, we contemplated the application of flow-chemistry. ${ }^{26}$ Recently, we developed a modular, and argon-driven flow platform especially designed for the robustification of late-stage transformations in natural product synthesis. ${ }^{27}$ In particular, gas reactions and photoreactions can be significantly accelerated and upscaled in flow. ${ }^{28}$ Therefore, we translated the oxidative cleavage of methoxyallene $\mathbf{1 5}$ to ester $\mathbf{1 6}$ into a flow process. After optimizing reaction parameters, the desired ester 16 was obtained in a slightly higher yield of $64 \%$ and a remarkably shorter reaction time of 60 minutes compared with 26 hours in batch (Scheme 4). Most importantly, in flow, this transformation could be conducted on a $56 \mathrm{mg}$ scale providing sufficient material for the final step of the synthesis.

cyclopentenone. The synthetic key challenge was to construct the unique bicyclic core motif in an efficient way, 


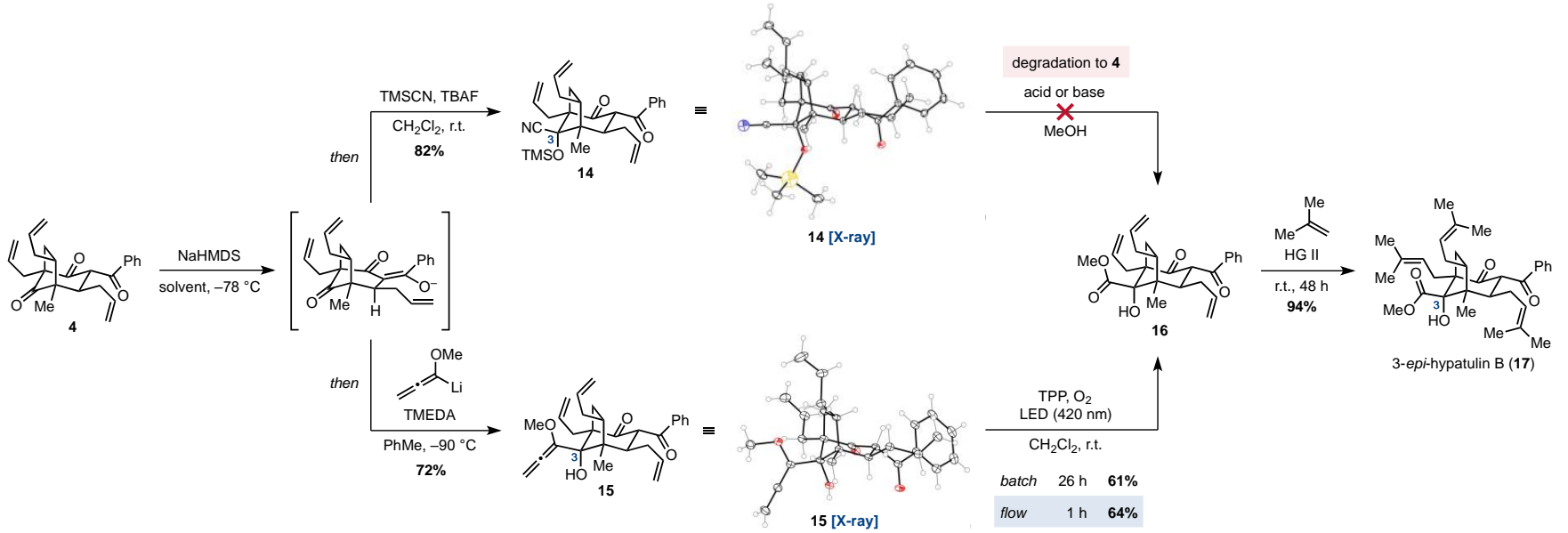

Ester 16 was then subjected to cross metathesis conditions. ${ }^{29}$ Initial reactions using 2-methyl-2-butene as a dimethylvinylcarbene source resulted in a mixture of products with dimethylated and monomethylated allyl groups. Therefore, the metathesis reaction was

performed with gaseous 2-methylpropene in a pressure tube providing 3-epi-hypatulin B (17) in $94 \%$ yield (Scheme 4). ${ }^{30}$

In conclusion we completed a synthesis of 3-epi-hypatulin B (17) in 16 steps starting from 2-which was achieved by introducing all required substituents to a cyclopentane core, followed by a Mukaiyama aldol cyclization. The introduction of the last carbonyl fragment lead to the undesired epimer of the tertiary alcohol. However, synthesis of 3-epi-hypatulin B could be achieved utilizing an oxidative cleavage of an enol ether species in presence of competing alkene functionalities. This reaction could be performed in flow allowing larger scale, shorter reaction time and a slightly higher yield. Our synthesis demonstrates the value of combining an efficient approach to a highly functionalized ring system with the virtue of flow chemistry for the robustification of late-stage transformations in natural product synthesis.

\section{ASSOCIATED CONTENT}

\section{Supporting Information.}

The Supporting Information is available free of charge on the ACS Publications website.

$X$-ray crystallographic data for 4 (CIF)

$X$-ray crystallographic data for (10R)-8 (CIF)

$X$-ray crystallographic data for 14 (CIF)

X-ray crystallographic data for 15 (CIF)

Experimental procedures and spectroscopic data (PDF)

\section{AUTHOR INFORMATION}

Corresponding Author

*E-mail: mathias.christmann@fu-berlin.de

\section{ORCID}

Mathias Christmann: 0000-0001-9313-2392

Notes

The authors declare no competing financial interest.

\section{ACKNOWLEDGMENT}

We thank Luise Schefzig and Bence Hartmayer (Freie Universität Berlin) for preparative support. We thank Dr. Daniel Franz for the recording of SCXRD data for compound 15. We would like to acknowledge the assistance of the Core Facility BioSupraMol supported by the DFG.

\section{REFERENCES}

(1) Shen, X.; Ting, C. P.; Xu, G.; Maimone, T. J. Programmable meroterpene synthesis. Nat. Commun. 2020, 11, 508.

(2) Yang, X.-W.; Grossman, R. B.; Xu, G. Research Progress of Polycyclic Polyprenylated Acylphloroglucinols. Chem. Rev. 2018, 118, 3508-3558.

(3) a) Tsukano, C.; Siegel, D. R.; Danishefsky, D. J. Differentiation of Nonconventional "Carbanions"-The Total Synthesis of Nemorosone and Clusianone. Angew. Chem. Int. Ed. 2007, 46, 88408844; b) Qi, J.; Porco, J. A. Rapid Access to Polyprenylated Phloroglucinols via Alkylative Dearomatization-Annulation: Total Synthesis of ( \pm )-Clusianone. J. Am. Chem. Soc. 2007, 129, 12682-12683; c) Biber, N.; Möws, K.; Plietker, B. The total synthesis of hyperpapuanone, hyperibone L, epi-clusianone and oblongifolin A. Nat. Chem. 2011, 3, 938-942; d) Bellavance, G.; Barriault, L. Total Syntheses of Hyperforin and Papuaforins $\mathrm{A}-\mathrm{C}$, and Formal Synthesis of Nemorosone through a Gold(I)-Catalyzed Carbocyclization. Angew. Chem. Int. Ed. 2014, 53, 6701-6704; e) Sparling, B. A.; Tucker, J. K.; Moebius, D. C.; Shair, M. D. Total Synthesis of (-)-Nemorosone and (+)-Secohyperforin. Org. Lett. 2015, 17, 3398-3401; f) Ting, C. P.; Maimone, T. J. The Total Synthesis of Hyperforin. Synlett 2016, 27, 1443-1449. 
(4) a) Gurevich, A. I.; Dobrynin, V. N.; Kolosov, M. N.; Popravko, S. A.; Ryabova, I. D.; Chernov, B. K.; Derbentseva, N. A.; Aizenman, B. E.; Garagulya, A. D. Hyperforin, an Antibiotic from Hypericum perforatum. Antibiotiki 1971, 16, 510-513; b) Bystrov, N. S.; Chernov, B. K.; Dobrynin, V. N.; Kolosov, M. N. The Structure of Hyperforin. Tetrahedron Lett. 1975, 16, 2791-2794; c) Beerhues, L. Hyperforin. Phytochemistry 2006, 67, 2201-2207; d) Richard, J.-A. Chemistry and Biology of the Polycyclic Polyprenylated Acylphloroglucinol Hyperforin. Eur. J. Org. Chem. 2014, 273-299.

(5) a) Liu, Y.-Y.; Ao, Z.; Xue, G.-M.; Wang, X.-B.; Luo, J.-G.; Kong, L.Y. Hypatulone A, a Homoadamantane-Type Acylphloroglucinol with an Intricately Caged Core from Hypericum patulum. Org. Lett. 2018, 20, 7953-7956; b) Zhang, Z.-Z.; Zeng, Y.-R.; Li, Y.-N.; Hu, Z.-X.; Huang, L.-J.; Gu, W.; Hao, X.-J.; Yuan, C.-M. Two new seco-polycyclic polyprenylated acylphloroglucinol from Hypericum sampsonii. Org. Biomol. Chem. 2021, 19, 216-219.

(6) Tanaka, N.; Yano, Y.; Tatano, Y.; Kashiwada, Y. Hypatulins A and B, Meroterpenes from Hypercium patulum. Org. Lett. 2016, 18, 5360-5363.

(7) Taber, D. F.; Gerstenhaber, D. A.; Berry, J. F. Enantioselective Conjugate Allylation of Cyclic Enones. J. Org. Chem. 2011, 76, 76147617.

(8) a) Rochin, C.; Babot, O.; Moulines, F.; Duboudin, F. Synthese Regioselective de Trisenoxysilanes. J. Organomet. Chem. 1984, 273, C7-C10; b) Cazeau, P.; Duboudin, F.; Babot, O.; Dunogues, J. A New Practical Synthesis of Silyl Enol Ethers: Part I. From Simple Aldehydes and Ketones. Tetrahedron 1987, 43, 2075-2088.

(9) Vaxelaire, C.; Winter, P.; Christmann, M. One-Pot Reactions Accelerate the Synthesis of Active Pharmaceutical Ingredients. Angew. Chem. Int. Ed. 2011, 50, 3605-3607.

(10) Hosomi, A.; Sakurai, H. Chemistry of organosilicon compounds. 99. Conjugate addition of allylsilanes to $\alpha, \beta$-enones. A New method of stereoselective introduc-tion of the angular allyl group in fused cyclic $\alpha, \beta$-enones. J. Am. Chem. Soc. $1977,99,1673-1675$.

(11) Xu, L.; Yang, M.; Qiu, H.; Lai, G.; Jiang, J. Efficient Iron-Catalyzed Sakurai-Michael Addition of Allyltrimethylsilane to Chalcones. Synth. Commun. 2008, 38, 1011-1019.

(12) Yadav, J. S.; Reddy, B. V. S.; Sadasiv, K.; Satheesh, G. 1,4-Conjugate addition of allyltrimethylsilane to $\alpha, \beta$-unsaturated ketones. Tetrahedron Lett. 2002, 43, 9695-9697.

(13) Lee, P. H.; Seomoon, D.; Kim, S.; Nagaiah, K.; Damle, S. V.; Lee, K. Efficient Addition of Allylsilanes to $\alpha, \beta$-Enones Using Catalytic Indium and Trimethylsilyl Chloride. Synthesis 2003, 2189-2193.

(14) Lee, P. H.; Lee, K.; Sung, S.-y.; Chang, S. The Catalytic Sakurai Reaction. J. Org. Chem. 2001, 66, 8646-8649.

(15) a) Dieckmann, W. Zur Kenntniss der Ringbildung aus Kohlenstoffketten. Ber. 1894, 27, 102-103; x) Wang, L.; Sun, L.; Wang, X.; Wu, R.; Zhou, H.; Zheng, C.; Xu, H. Me ${ }_{2}$ AlSEt-Promoted Domino Dieckmann Cyclization Enables the Total Synthesis of Polycyclic Polyprenylated Acylphloroglucinols. Org. Lett. 2019, 21, 8075-8079.

(16) Crystal structures of compounds 4, 14 and 15 were only obtained from racemic mixtures, since preliminary studies were conducted from the racemate of silyl enol ether $\mathbf{6}$ (see Supporting Information). Compounds $\mathbf{1 3}$ was only obtained as a racemate as well.

(17) a) Mukaiyama, T.; Koichi, N.; Kazuo, B. NEW ALDOL TYPE REACTION. Chem. Lett. 1973, 2, 1011-1014; b) Li, C.; Tu, S.; Wen, S.; Li, S.; Chang, J.; Shao, F.; Lei, X. Total Synthesis oft he G2/M DNA Damage Checkpoint Inhibitor Psilostachyin C. J. Org. Chem. 2011, 76, 3566-3570.

(18) Dess, D. B.; Martin, J. C. Readily accessibl 12-I-5 oxidant for the conversion of primary and secondary alcohols to aldehydes and ketones. J. Org. Chem. 1983, 48, 4155-4156.

(19) Hase, T. A.; Koskimies, J. K. A Compilation of References on Formyl and Acyl Anion Synthons. Aldrichimica Acta, 1981, 14, 73-77.
(20) a) Seebach, D.; Corey, E. J. Generation and synthetic applications of 2-lithio-1,3-dithianes. J. Org. Chem. 1975, 40, 231-237; b) Gröbel, B.-T.; Seebach, D. Umpolung of the Reactivity of Carbonyl Compounds Through Sulfur-Containing Reagents. Synthesis 1977, 357-402; c) Yus, M.; Nájera, C.; Foubelo, F. The role of 1,3-dithianes in natural product synthesis. Tetrahedron 2003, 59, 6147-6212; d) Smith, A. B.; Adams, C. M. Evolution of Dithiane-Based Strategies for the Construction of Architecturally Complex Natural Products. Acc. Chem. Res. 2004, 37, 365-377.

(21) For reviews of lithiated methoxyallenes as building blocks and carbonyl carbanion equivalents, see: a) Zimmer, R. Alkoxyallenes - Building Blocks in Organic Synthesis. Synthesis 1993, 165178; b) Zimmer, R.; Reissig, H.-U. Alkoxyallenes as Building Blocks for Organic Synthesis. Chem. Soc. Rev. 2014, 43, 2888-2903.

(22) For examples of oxidative cleavage of methoxyallenes, see: a) Zimmer, R.; Taszarek, M.; Schefzig, L.; Reissig, H.-U. Reaction of a Polycyclic Diketone with Lithiated Methoxyallene: Synthesis of New Functionalized Cage Compounds. Synlett 2008, 2046-2050; b) Bressel, B.; Reissig, H.-U. A New Approach to Neuraminic Acid Analogoues via 1,2-Oxazines. Org. Lett. 2009, 11, 527-530.

(23) a) Coulthard, G.; Erb, W.; Aggarwal, V. K. Stereocontrolled organocatalytic synthesis of prostaglandin $\mathrm{PGF}_{2 \alpha}$ in seven steps. $\mathrm{Na}$ ture 2012, 489, 278-281; b) Fisher, T. J.; Dussault, P. H. Alkene ozonolysis. Tetrahedron 2017, 73, 4233-4258.

(24) Jefford, C. W.; Kohmoto, S.; Boukouvalas, J.; Burger, U. Reaction of Singlet Oxygen with Enol Ethers in the Presence of Acetaldehyde. Formation of 1,2,4-Trioxanes. J. Am. Chem. Soc. 1983, 105, 6498-6499.

(25) a) Sivaguru, J.; Saito, H.; Poon, T.; Omonuwa, T.; Franz, R.; Jockusch, S.; Hooper, C.; Inoue, Y.; Adam, W.; Turro, N. J. Stereoselective Photooxidation of Enecarbamates: Reactivity of Ozone vs Singlet Oxygen. Org. Lett. 2005, 7, 2089-2092; b) Bayer, P.; Pérez-Ruiz, R.; Jacobi von Wangelin, A. Stereoselective Photooxidations by the Schenck Ene Reaction. ChemPhotoChem 2018, 2, 559-570; c) Bayer, P.; Schachtner, J.; Májek, M.; Jacobi von Wangelin, A. Visible lightmediated photo-oxygenation of arylcyclohexenes. Org. Chem. Front. 2019, 6, 2877-2883.

(26) a) Pastre, J. C.; Browne, D. L.; Ley, S. V. Flow chemistry syntheses of natural products. Chem. Soc. Rev. 2013, 42, 8849-8869; b) Plutschack, M. B.; Pieber, B.; Gilmore, K.; Seeberger, P. H. The Hitchhiker's Guide to Flow Chemistry. Chem. Rev. 2017, 117, 1179611893.

(27) Kleoff, M.; Schwan, J.; Christmann, M.; Heretsch, P. A Modular, Argon-Driven Flow Platform for Natural Product Synthesis and Late-Stage Transformations. Org. Lett. 2021, 23, 2370-2374.

(28) a) Su, Y.; Straathof, N. J. W.; Hessel, V.; Noël, T. Photochemical Transformations Accelerated in Continuous-Flow Reactors: Basic Concepts and Applications. Chem. Eur. J. 2014, 20, 10562-10589; b) Ghogare, A. A.; Greer, A. Using Singlet Oxygen to Synthesize Natural Products and Drugs. Chem. Rev. 2016, 116, 9994-10034; c) Cambié, D.; Bottecchia, C.; Straathof, N. J. W.; Hessel, V.; Noël, T. Applications of Continuous-Flow Photochemistry in Organic Synthesis, Material Science, and Water Treatment. Chem. Rev. 2016, 116, 10276-10341; d) Mallia, C. J.; Baxendale, I. R. The Use of Gases in Flow Synthesis. Org. Process Res. Dev. 2016, 20, 327-360.

(29) a) Schuster, M.; Blechert, S. Olefin Metathesis in Organic Chemistry. Angew. Chem. Int. Ed. Engl. 1997, 36, 2036-2056; b)Fürstner, A. Olefin Metathesis and Beyond. Angew. Chem. Int. Ed. 2000, 39, 3012-3043; c) Chatterjee, A. K.; Choi, T.-L.; Sanders, D. P.; Grubbs, R. H. A General Model for Selectivity in Olefin Cross Metathesis. J. Am. Chem. Soc. 2003, 125, d) Grubbs, R. H. Olefin metathesis. Tetrahedron 2004, 60, 7117-7140;

(30) Uwamori, M.; Nakada, M. Stereoselective total synthesis of $( \pm)$-hyperforin via intramolecular cyclopropanation. Tetrahedron Lett. 2013, 54, 2022-2025. 